\title{
Palladium(II)- $\eta^{3}$-allyl complexes bearing $\mathrm{N}$-trifluoromethyl $\mathrm{N}$ - heterocyclic carbenes: a new generation of anticancer agents which restrain the growth of high grade serous ovarian cancer tumoroids
}

\author{
[a] Dr. T. Scattolin \\ Department of Chemistry and Centre for Sustainable Chemistry \\ Ghent University \\ Krijgslaan 281,S-3, 9000 Ghent, Belgium \\ E-mail: thomas.scattolin@ugent.be \\ [b] E. Bortolamiol, Prof. Dr. F. Visentin, Prof. Dr. F. Rizzolio \\ Department of Molecular Sciences and Nanosystems \\ Università Ca' Foscari \\ Campus Scientifico Via Torino 155, 30174, Venezia-Mestre, Italy \\ E-mail: fvise@unive.it \\ [c] Dr. S. Palazzolo, Dr. I. Caligiuri, Dr. T. Perin, Prof. Dr. V. Canzonieri, \\ Prof. Dr. F. Rizzolio \\ Pathology Unit, Department of Molecular Biology and Translational \\ Research \\ Centro di Riferimento Oncologico di Aviano (CRO) IRCCS \\ via Franco Gallini 2, 33081, Aviano, Italy
}

Thomas Scattolin, ${ }^{[a]}$ Enrica Bortolamiol, ${ }^{[b]}$ Fabiano Visentin, ${ }^{* b]}$ Stefano Palazzolo, ${ }^{[c]}$ Isabella Caligiuri, ${ }^{[c]}$ Tiziana Perin,,$^{[\mathrm{c}]}$ Vincenzo Canzonieri, ${ }^{[\mathrm{c}, \mathrm{d}]}$ Nicola Demitri[e], Flavio Rizzolio ${ }^{[\mathrm{b}, \mathrm{c}]}$ and Antonio Togni ${ }^{*[\mathrm{f}]}$

\begin{abstract}
The first palladium organometallic compounds bearing $\mathrm{N}$ trifluoromethyl $\mathrm{N}$-heterocyclic carbenes have been synthesized. These $\eta^{3}$-allyl complexes are potent antiproliferative agents against different cancer lines (the most part of $I C_{50}$ falls in the range of 0.02 $0.5 \mu \mathrm{M})$ and by choosing PTA as co-ligand, we can improve the selectivity toward tumor cells, whereas the introduction of 2-methyl substituents generally slightly reduces the antitumor activity.

A series of biochemical assays, aimed at defining the cellular targets of these palladium complexes, has shown that mitochondria are damaged before DNA, therefore revealing a behavior substantially different from that of cisplatin and derivatives

We assume that the specific mechanism of action of these organometallic compounds involves the nucleophilic attack on the $\eta^{3}$ allyl fragment.

The effectiveness of the representative complex $4 c$ has been verified on ovarian cancer tumoroids derived from patients. The results are promising: contrary to carboplatin, our compound resulted very active and showed a low toxicity toward normal liver organoids.
\end{abstract}

\section{Introduction}

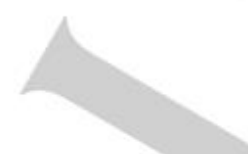

Cancer represents a widespread and heterogeneous class of pathologies that in 2018 have caused approximately 10 million deaths worldwide, ${ }^{[1]}$ despite the different therapeutic approaches currently available.

Nowadays about half of the patients are treated with chemoradiotherapy ${ }^{[2]}$ and the most part of protocols requires the use of platinum-based antineoplastic agents. ${ }^{[3]}$ In spite of this, cisplatin ${ }^{[4]}$ and its second and third generation derivatives, ${ }^{[5]}$ have shown some severe limitations ascribable above all to side effects on kidneys, liver and brain and intrinsic or acquired resistance observed in some types of cancer. ${ }^{[6]}$ These limitations have stimulated researchers to develop alternative drugs based on [d] Prof. Dr. V. Canzonieri

Department of Medical, Surgical and Health Sciences

Università degli Studi di Trieste

Strada di Fiume 447, Trieste, Italy

[e] Dr. N. Demitri

Area Science Park

Elettra-Sincrotrone Trieste, S.S. 14 Km 163.5,

Basovizza, 34149, Trieste, Italy.

[f] Prof. Dr. A. Togni

Department of Chemistry and Applied Biosciences

Swiss Federal Institute of Technology, ETH Zürich

Vladimir-Prelog-Weg 2, CH-8093 Zurich, Switzerland

E-mail: antonio.togni@inorg.chem.ethz.ch

Supporting information for this article is given via a link at the end of the document.

transition metals different from platinum and, among these, palladium complexes have gained increased interest. As a matter of fact, some derivatives of this metal described in the literature have shown good antiproliferative activity toward several tumor cell lines. Moreover, their mode of action appears sometime quite different from that of cisplatin and analogues. ${ }^{[7]}$<smiles></smiles>
Huq (2007) ${ }^{7 \mathrm{~b}}$<smiles></smiles>

Che (2016) ${ }^{7 e}$

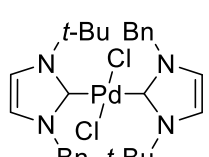
Bn $t$-Bú

Gosh $(2007)^{7 d}$<smiles>CN1Cc2ccccc2[P-]1(Cl)[In]</smiles>

Spencer (2009) ${ }^{7 \mathrm{c}}$
Figure 1. Some palladium-based complexes as potential anticancer agents. ${ }^{[7]}$

Some of the most active palladium compounds are equipped with $\mathrm{N}$-heterocyclic carbenes (NHCs) ${ }^{[7 \mathrm{~d}-\mathrm{e}]}$ (Figure 1). These ligands, widely employed in homogenous catalysis,$^{[8]}$ are able to strongly stabilize complexes with different transition metals and this property can be exploited to avoid a fast decomposition of the metal-based drug in a biological environment. For this reason, NHCs play now a significant role also in medicinal chemistry, as highlighted by numerous published papers. ${ }^{[9]}$ The strength of the metal-carbene bond can be mainly ascribed to the good $\sigma$ electron donating ability of NHCs. However, recent works have highlighted the importance of metal-carbene $\pi$-back-donation in 
the activity of NHC-based transition metal catalysts. ${ }^{[10]}$ This feature can be enhanced with the introduction of electronwithdrawing groups in the backbone structure or on the nitrogen substituents of the NHCs. ${ }^{[11]}$ Trifluoromethyl is an excellent electron-attracting group because of hyperconjugation between the nitrogen lone pair and the $\sigma^{*} \mathrm{C}-\mathrm{F}$ antibonding orbitals. ${ }^{[11]}$ In this respect, one of us have recently described the synthesis of $N$ trifluoromethyl carbenes and their application as ligands in efficient ruthenium-based catalysts for olefin metathesis. ${ }^{[12 b-c]}$ Furthermore, it is well-established that the introduction of groups containing fluorine atoms, especially perfluorinated fragments, may significantly alter the pharmacological properties of the compounds under investigation. ${ }^{[13]}$

In addition to $\mathrm{N}$-trifluoromethyl $\mathrm{NHCs}$, we have adopted PTA (1,3,5-triaza-7-phosphaadamantane) as further spectator ligand for our palladium complexes, with the aim to enhance their compatibility with the biological environment. This phosphine is well-known for its high water-solubility, a property that is generally transferred also to its complexes with transition metals. ${ }^{[14]}$

Moreover, in this paper the biological activity of PTA complexes has been then compared with that one of the homologous compounds containing the "classical" triphenylphosphine.

Finally, the two remaining palladium(II) coordination sites were occupied by the $\eta^{3}$-allyl fragment. The reactivity of $\mathrm{Pd}\left(\eta^{3}\right.$-allyl) complexes $^{[15]}$ and their use as excellent catalysts in crosscoupling reactions ${ }^{[16]}$ have been extensively studied.

The anticancer activity of complexes containing the $\mathrm{Pd}(\mathrm{II})-\eta^{3}$-allyl organometallic function, was explored for the first time by some of us in a recent work, in which purine-based NHCs were employed as spectator ligands. ${ }^{[17]}$

Their cytotoxicity toward the A2780 and SKOV-3 ovarian cancer lines, if compared with those obtained for complexes with the same spectator ligands but containing the palladacyclopentadienyl and $\operatorname{Pd}(0)-\eta^{2}$-olefin fragments, ${ }^{[18]}$ appeared very promising both in terms of antiproliferative and proapoptotic activity.

Therefore, hoping that the combination of all these positive factors allows to give the best result we have synthesized and exhaustively characterized the novel compounds shown in Scheme 1 and tested their efficiency and selectivity as anticancer agents against different human tumor cell lines.

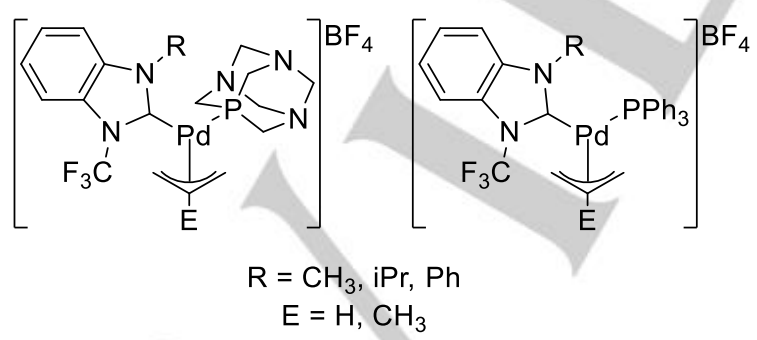

Scheme 1. $\eta^{3}$-allyl Palladium complexes bearing $N$-trifluoromethyl NHCs and phosphines $\left(\mathrm{PPh}_{3}\right.$ or PTA) synthesized in this work

One of the most promising compounds was evaluated in normal liver organoids and ovarian cancer organoids (tumoroids) derived directly from patients. Organoids are lab-built mini-organs that can act as models to recapitulate cancer development.
The availability of innovative biobanks of tumoroids/organoids represents a revolutionary tool to study protein function in the onset and development of cancer ${ }^{[19]}$ or to develop innovative therapies. ${ }^{[20]}$ In this regard, most researchers are modelling ovarian cancer utilizing commercially available cancer cell lines sensitive or resistant to platinum treatments. But innate or acquired chemoresistance together with tumor heterogeneity are the causes of therapeutic failure in ovarian cancer ${ }^{[21]}$ and innovative preclinical models are required to solve this complexity. A few leading groups in this field are developing animal ${ }^{[22]}$ and ex vivo organoid ${ }^{[23,24]}$ models of ovarian cancer to better mimic treatment options.

Finally, a series of experiments were then carried out with the aim to define the cellular target of the compounds, proving that their mechanism of action is different from that one of cisplatin.

\section{Results and Discussion}

\section{Synthesis of $\mathbf{N}$-trifluoromethyl benzimidazolium salts a-c}

The $N$-trifluoromethyl benzimidazolium salts a-c, which are the precursors of the carbene ligands studied in this work, were synthesized by alkylation or arylation of $\mathrm{N}$-trifluoromethyl benzimidazole. In turn, this reagent can be obtained on a multigram scale by electrophilic trifluoromethylation of benzimidazole with trifluoromethyl-1,3-dihydro-3,3-dimethyl-1,2benziodoxole as depicted in Scheme $2 .{ }^{[11 b]}$

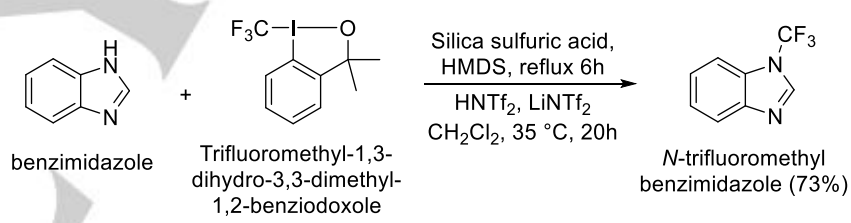

Scheme 2. Synthesis of $N$-trifluoromethyl benzimidazole

In order to make the comparison among the anticancer activities of the final cationic allyl palladium species more reliable, it was decided to maintain in all cases the same counterion (tetrafluoroborate).

Therefore, the synthesis of compound a was carried out by reacting, under the conditions reported in Scheme $3, \mathrm{~N}$ trifluoromethyl benzimidazole with a slight excess of $\mathrm{Me}_{3} \mathrm{OBF}_{4}$ (Meerwein's salt). Compound $\mathbf{b}$ was obtained by reacting silver tetrafluoroborate with a stoichiometric amount of 3-isopropyl-1(trifluoromethyl)-benzimidazolium iodide, which in turn was synthesized starting from 2-iodopropane and $\mathrm{N}$-trifluoromethyl benzimidazole according to the protocol reported in the literature. ${ }^{[11 b]}$ After filtration of the silver iodide, compound $\mathbf{b}$ was isolated by precipitation with diethyl ether.

Finally, the benzimidazolium salt $\mathbf{c}$ was obtained, as described in a previous paper, ${ }^{[11 \mathrm{~b}]}$ by arylation of $\mathrm{N}$-trifluoromethyl benzimidazole with $\mathrm{Ph}_{2} \mathrm{IBF}_{4}$, using copper(II) triflate as catalyst (Scheme 3). 


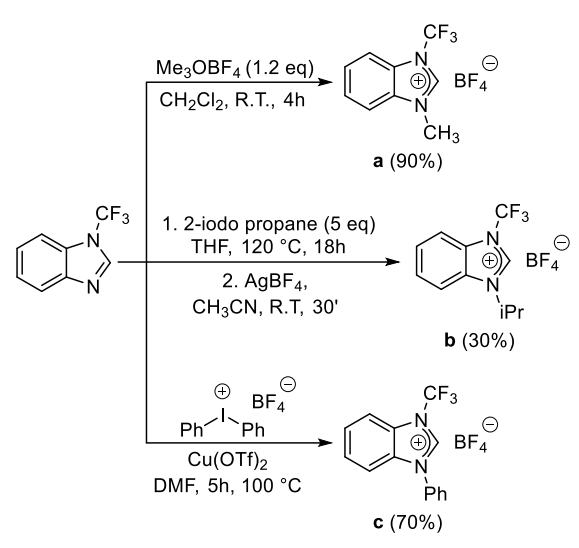

Scheme 3. Synthesis of $N$-trifluoromethyl benzimidazolium salts (a-c)

\section{Synthesis of $\eta^{3}$-allyl palladium complexes stabilized by $N$ trifluoromethyl NHCs}

The synthesis of the mixed $\mathrm{NHC} / \mathrm{PPh}_{3}$ palladium $\eta^{3}$-allyl complexes 1a-c and 2a-c was performed in a one-pot process, by reacting the starting benzimidazolium salts a-c with 0.5 equivalents of silver oxide in acetonitrile and, after seven hours, adding the palladium allyl precursor $\left(\left[\mathrm{Pd}(\mu-\mathrm{Cl})\left(\eta^{3}-\mathrm{C}_{3} \mathrm{H}_{5}\right)\right]_{2}\right.$ or $\left.\left[\mathrm{Pd}(\mu-\mathrm{Cl})\left(\mathrm{n}^{3}-2-\mathrm{MeC}_{3} \mathrm{H}_{4}\right)\right]_{2}\right)$ and $\mathrm{PPh}_{3}$ to the reaction mixture (Scheme 4).

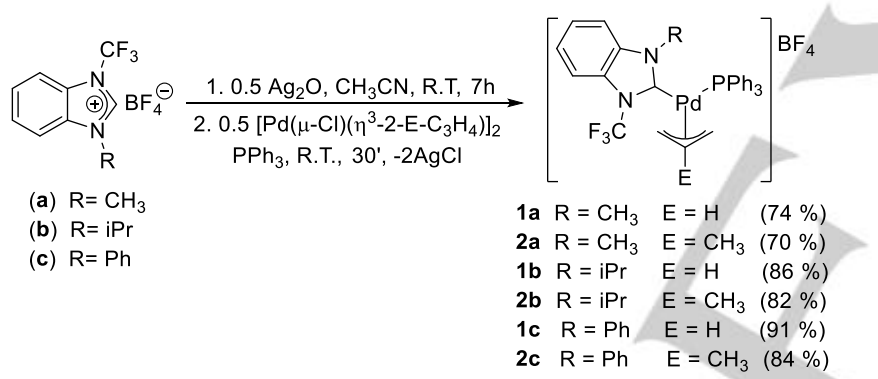

\begin{abstract}
2a $\mathrm{R}=\mathrm{CH}_{3} \quad \mathrm{E}=\mathrm{CH}_{3}(70 \%)$
1b $\mathrm{R}=\mathrm{iPr} \quad \mathrm{E}=\mathrm{H} \quad(86 \%)$

2b $\mathrm{R}=\mathrm{iPr} \quad \mathrm{E}=\mathrm{CH}_{3}(82 \%)$

1c $\mathrm{R}=\mathrm{Ph} \quad \mathrm{E}=\mathrm{H} \quad(91 \%)$
\end{abstract}

Scheme 4. Synthesis of $\eta^{3}$-allyl Pd complexes bearing $N$-trifluoromethyl NHCs and $\mathrm{PPh}_{3}$

This approach was adopted because of the difficulty in isolating the NHC-silver(I) complexes in pure form and in good yields.

The six new mixed $\mathrm{NHC} / \mathrm{PPh}_{3}$ palladium compounds were easily isolated and exhaustively characterized by IR and NMR spectroscopies and elemental analysis.

Examination of NMR spectra reveals that every isolated $\eta^{3}$-allyl palladium derivative is composed of a couple of atropoisomers (exo and endo, see Figure 2), owing to the hindered rotation of the asymmetric carbenes around the $\mathrm{Pd}-\mathrm{C}$ bond. This phenomenon, already observed for similar compounds, ${ }^{[15 i, 17]}$ is evidenced by two distinct set of signals in the corresponding NMR spectra.

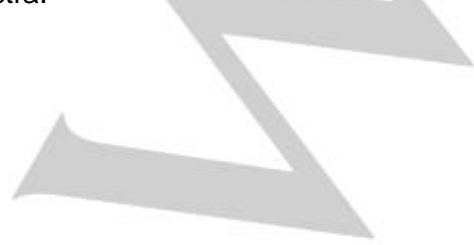

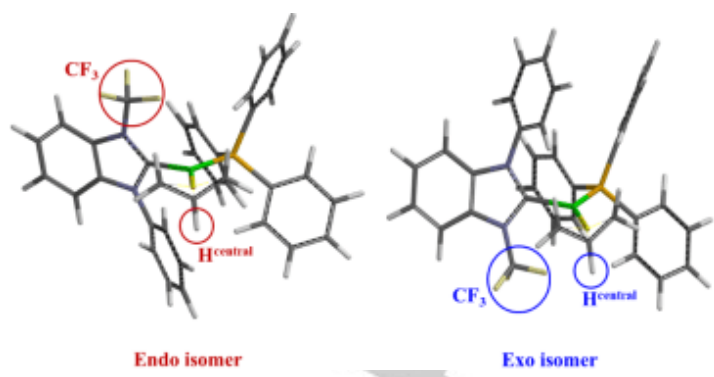

Figure 2. Representation of the two atropoisomers related to compound 1c (DFT calculations).

Moreover, the presence in the ${ }^{1} \mathrm{H}-\mathrm{NMR}$ spectra of five different signals ascribable to the allyl protons for each atropoisomer demonstrates that, if active, the typical $\eta^{3}-\eta^{1}-\eta^{3}$ or syn-syn/antianti rearrangements are slow in the NMR time scale (Figure S6). The coordination of the triphenylphosphine is demonstrated by the appearance in the ${ }^{31} \mathrm{P}\{1 \mathrm{H}\}$-NMR spectra of two sharp quartets $\left(\mathrm{J}_{\mathrm{P}-\mathrm{F}}=1-4 \mathrm{~Hz}\right)$ at ca. $25 \mathrm{ppm}$ (Figure S7), whereas that one of $\mathrm{N}$ heterocyclic carbene is confirmed by the presence in the ${ }^{13} \mathrm{C}\left\{{ }^{1} \mathrm{H}\right\}$ NMR spectra of two multiplets (one for each atropoisomer) at about $190 \mathrm{ppm}$ attributable to the carbenic carbon. The multiplicity of the signals is consequence of the simultaneous coupling of the carbon with phosphorus and fluorine nuclei (Figure S8).

Finally, ${ }^{19} \mathrm{~F}\left\{{ }^{1} \mathrm{H}\right\}-N M R$ spectra exhibit the two doublets of the $\mathrm{CF}_{3}$ groups at about $-55 \mathrm{ppm}\left(\mathrm{J}_{\mathrm{F}-\mathrm{P}}=1-4 \mathrm{~Hz}\right)$ and the signals of tetrafluoroborate counterion at about $-153 \mathrm{ppm}$ (Figure S9).

The mixed NHC/PTA palladium $\eta^{3}$-allyl compounds $\mathbf{3 a - c}$ and $4 \mathbf{4 a -}$ c were prepared in an analogous manner as for the compounds containing the triphenylphosphine (Scheme 5).

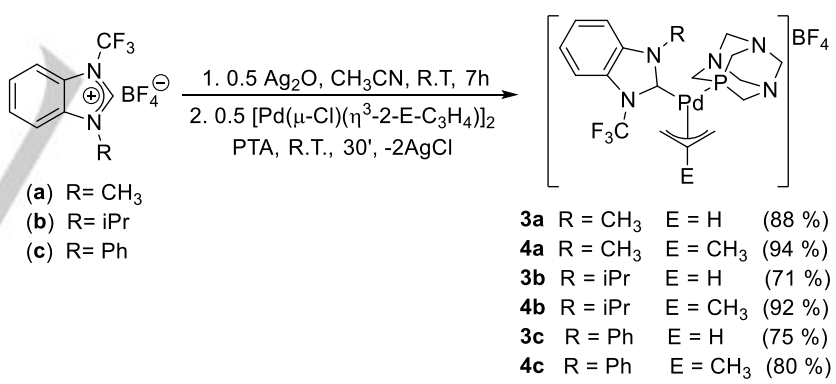

Scheme 5. Synthesis of $\eta^{3}$-allyl Pd complexes bearing $N$-trifluoromethyl NHCs and PTA

Also for each one of these compounds the presence in solution of a pair of atropoisomers is confirmed. In particular, in the ${ }^{1} \mathrm{H}-\mathrm{NMR}$ spectra (Figure S34), the allyl fragment gives rise to five distinct allyl signals (for each isomer), whereas the methylene protons of PTA $\left(\mathrm{NCH}_{2} \mathrm{~N}\right.$ and $\left.\mathrm{NCH}_{2} \mathrm{P}\right)$ bring about two multiplets between 4 and $5 \mathrm{ppm}$. The coordination of PTA is also corroborated by the two superimposed quartets $\left(J_{P-F}=1-5 \mathrm{~Hz}\right)$ at about $-58 \mathrm{ppm}(\Delta \delta$ $\approx 50 \mathrm{ppm}$ with respect to the uncoordinated PTA), observed in the ${ }^{31} \mathrm{P}\left\{{ }^{1} \mathrm{H}\right\}-\mathrm{NMR}$ spectra (Figure S35).

\section{X-Ray Crystal Structure Determination of 1c}

Crystalline 1c contains one crystallographically independent palladium complex (Figure 3). The palladium center adopts a square planar coordination geometry with bond lengths and 
angles in agreement with literature structural data of similar complexes (Table S1), such as e.g. triphenylphosphine-( $\eta^{3}$-allyl)(1,3,7,9-tetramethylxanthinium-8-ylidene)-palladium tetrafluoroborate (CCDC 1825948). ${ }^{[17 a]}$ The complex bears a positive charge that is balanced by a $\mathrm{BF}_{4}$ counterion, located close to the allyl ligand, which represent the area where the metal is more exposed (shortest F...Pd contacts are 3.88(1) $\AA$ in 1c and 3.50(1) A in CCDC 1825948).

Molecular model of $\mathbf{1 c}$ is well superimposable with triphenylphosphine-( $\eta^{3}$-allyl)-(1,3,7,9-tetramethylxanthinium-8ylidene)-palladium tetrafluoroborate (CCDC 1825948, see Figure S54) with minimal shifts of atoms directly bound to the metal and equivalent xanthine and allyl arrangements (R.M.S.D. $\sim 0.14 \AA$ ). This comparison highlights the phosphine ligand conformational freedom, which is influenced by crystal packing contacts and relative bulkiness of xanthine substituents. Crystal packing of 1c shows hydrophobic contacts among neighbour molecules, involving weak intermolecular interactions: $\pi \cdots \pi$ (i.e. $\mathrm{d}_{\pi \cdots \pi}=$ 3.778(1) $\AA$ with $0.82 \AA$ slippage between ring centroids) and $\mathrm{CH} \cdots \pi$ (i.e. $\mathrm{d}_{\mathrm{CH} \cdots \pi}=3.663(2) \AA$ with $63^{\circ}$ between $\mathrm{CH}$ and $\pi$-plane), among neighbour aromatic sidechains. $A$ well oriented intramolecular $\mathrm{CH} \cdots \pi$ contact in $1 \mathrm{c}\left(\mathrm{d}_{\mathrm{CH} \cdots \pi}=3.678(2) \AA\right.$ with $45^{\circ}$ between $\mathrm{CH}$ and $\pi$-plane) involves xanthine lateral phenyl substituent and one phosphinic phenyl and probably restrains the conformation adopted by the ligands. The $\eta^{3}$-allyl instead can adopt two nearly equally probable configurations specular with respect to the Pd coordination plane.
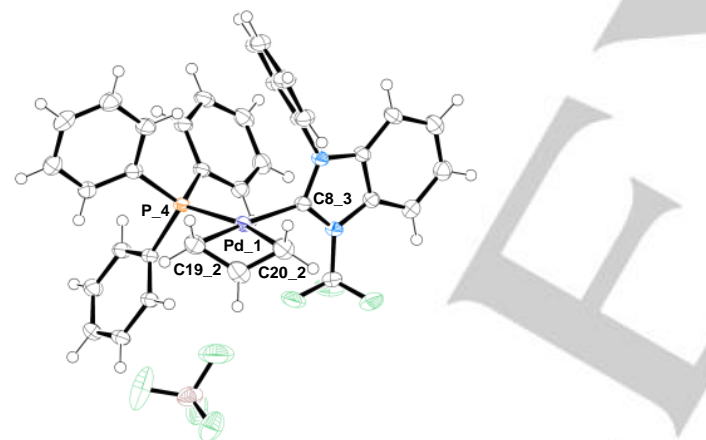

Figure 3. Ellipsoid representation of 1c crystal ASU content (50\% probability). Atom labels in use for Pd coordination sphere are reported. Disorder omitted

$$
\text { for clarity. }
$$

\section{Anticancer activity on human cancer and normal cell lines}

In a preliminary phase, we have monitored the stability of the palladium complexes in $1: 1$ DMSO-d $6 / \mathrm{D}_{2} \mathrm{O}$ solution by NMR spectroscopy. After 24 and 48 hours no significant changes of the spectra are observable, indicating that the complexes retain their structural integrity.

Nevertheless, the ${ }^{31} \mathrm{P}-\mathrm{NMR}$ spectra collected in the presence of reduced glutathione (GSH) reveal a relevant reactivity of the mixed $\mathrm{NHC} / \mathrm{PPh}_{3}$ complexes with this important biological thiol. In further detail, the signal of the complex 1c (at concentration 0.2 $\mathrm{mM}$ in presence of $\mathrm{GSH} 1 \mathrm{mM}$ and at $\mathrm{pH} \approx 7$ ) disappear completely within 24 hours, replaced by that one of triphenylphosphinoxide (Figure S55). Triphenylphosphinoxide might be one of final products of decomposition of the unstable complex $\mathrm{NHC}-\mathrm{Pd}^{0}-\mathrm{PPh}_{3}$, which is normally obtained as a result of the nucleophilic attack by an amino or thiol group on the coordinated allyl ligand. ${ }^{[15]}$

On the contrary, under the same conditions the mixed NHC/PTA complex $3 c$ does not react appreciably with GSH after 24 hours as confirmed monitoring the process by ${ }^{1} \mathrm{H}$ and ${ }^{31} \mathrm{P}$ NMR spectroscopies (Figures S56-57).

In order to investigate the potential anticancer activity of the mixed $\mathrm{NHC} / \mathrm{PPh}_{3}$ and NHC/PTA allyl palladium complexes, a panel of six different human tumor cell lines (ovarian cancers OVCAR5, A2780, with its cisplatin resistant clone A2780cis, lung cancer A549, colon cancer DLD1 and malignant melanoma A375) and MRC-5 normal cells (human lung fibroblasts) were treated for 96 hours with our compounds and cisplatin (positive control). In Table 1 are reported the resulting half inhibitory concentrations $\left(\mathrm{IC}_{50}\right)$ values.

First of all, Table 1 highlights that, with the exception of some rare cases, the tested compounds are more (and often much more) cytotoxic than cisplatin in all six tumor cell lines taken into consideration.

Secondly, the antiproliferative activity exerted by each compound on the A2780 (cisplatin-sensitive ovarian cancer) and A2780cis (cisplatin-resistant ovarian cancer) cell lines is substantially comparable, therefore suggesting a different mechanism of action from cisplatin (DNA platination).

Moreover, it is possible to notice how, with the same ancillary ligands, the compounds bearing the $\mathrm{Pd}(\mathrm{II})$-2-methylallyl organometallic fragment (2a-c and $\mathbf{4 a - c}$ ) are generally less active than those bearing the $\mathrm{Pd}(\mathrm{II})$-allyl fragment (1a-c and 3a-c). This evidence seems to suggest that the lower tendency of the $\mathrm{Pd}(\mathrm{II})$ 2-methylallyl substrates compared to the $\mathrm{Pd}(\mathrm{II})$-allyl ones to undergo nucleophilic attack on the terminal allyl carbons, as reported in many published papers ${ }^{[15]}$ might be correlated to their lower anticancer activity. As a matter of fact, we suppose that a plausible mechanism of action of our palladium complexes might involve a nucleophilic attack of some group present in the main biotarget (i.e. amino or thiol group) to the allyl fragment and the consequent allylation of the involved biomolecule could compromise its functionality. This kind of reactivity of palladium allyl compounds, is well known and exploited in important crosscoupling processes (i.e. Tsuji-Trost reaction).

It is also noteworthy that, with the same allyl fragment and carbene ligand, the complexes bearing the 1,3,5-triaza-7phosphadamantane (PTA) are generally slightly less active on the tumor lines than the triphenylphosphine analogues, but the mixed NHC/PTA derivatives have the great advantage of being poorly active or inactive against normal cells (MRC-5 fibroblasts) namely the slight loss of cytotoxicity allows to gain in selectivity against cancer cells. Moreover, the lower activity of the mixed NHC/PTA complexes, which is probably due to their lower reactivity toward nucleophiles present in the biological environment (the strong $\sigma$ electron releasing capability of PTA partially inhibits the electrophilicity of the allyl fragment), might help such compounds to reach unaltered the biotarget.

On the other hand, based on the reactivity shown with GSH (vide supra), the marked activity of the mixed $\mathrm{NHC} / \mathrm{PPh}_{3}$ complexes even on normal cells could be ascribed to their propensity to form triphenylphosphinoxide, which is known to have a certain intrinsic toxicity. ${ }^{[25]}$ 
Table 1. Effects of the Pd-complexes on the proliferation of several cancer and normal cell lines. ${ }^{[\mathrm{a}]}$

\begin{tabular}{|c|c|c|c|c|c|c|c|}
\hline \multirow{2}{*}{ Complex } & \multicolumn{7}{|c|}{$\mathrm{IC}_{50}(\mu \mathrm{M})$} \\
\hline & A2780 & A2780cis & OVCAR-5 & A549 & A375 & DLD1 & MRC-5 \\
\hline Cisplatin & $0.81 \pm 0.06$ & $43 \pm 5$ & $5.2 \pm 0.8$ & $6 \pm 2$ & $4.7 \pm 0.4$ & $19 \pm 4$ & $14 \pm 1$ \\
\hline $1 \mathrm{a}$ & $0.03 \pm 0.01$ & $0.051 \pm 0.004$ & $0.26 \pm 0.03$ & $0.18 \pm 0.09$ & $0.041 \pm 0.003$ & $0.28 \pm 0.06$ & $0.28 \pm 0.01$ \\
\hline $2 a$ & $0.14 \pm 0.03$ & $0.08 \pm 0.02$ & $0.30 \pm 0.05$ & $0.14 \pm 0.06$ & $0.083 \pm 0.009$ & $0.31 \pm 0.04$ & $1.8 \pm 0.6$ \\
\hline $1 b$ & $0.024 \pm 0.002$ & $0.027 \pm 0.004$ & $0.20 \pm 0.06$ & $0.17 \pm 0.01$ & $0.045 \pm 0.005$ & $0.28 \pm 0.01$ & $0.30 \pm 0.05$ \\
\hline $2 b$ & $0.18 \pm 0.05$ & $0.12 \pm 0.02$ & $0.5 \pm 0.1$ & $0.32 \pm 0.05$ & $0.24 \pm 0.02$ & $0.50 \pm 0.09$ & $1.5 \pm 0.3$ \\
\hline 1c & $0.024 \pm 0.006$ & $0.096 \pm 0.005$ & $0.10 \pm 0.01$ & $0.029 \pm 0.002$ & $0.028 \pm 0.004$ & $0.31 \pm 0.01$ & $0.25 \pm 0.05$ \\
\hline 2c & $0.043 \pm 0.009$ & $0.24 \pm 0.04$ & $0.04 \pm 0.01$ & $0.030 \pm 0.004$ & $0.034 \pm 0.004$ & $0.36 \pm 0.07$ & $0.25 \pm 0.03$ \\
\hline $3 a$ & $0.23 \pm 0.07$ & $0.9 \pm 0.2$ & $10 \pm 1$ & $10 \pm 3$ & $0.286 \pm 0.006$ & $1.11 \pm 0.09$ & $>100$ \\
\hline $4 a$ & $0.25 \pm 0.01$ & $1.4 \pm 0.1$ & $6 \pm 1$ & $2.1 \pm 0.1$ & $1.7 \pm 0.3$ & $48 \pm 29$ & $>100$ \\
\hline $4 b$ & $0.76 \pm 0.01$ & $1.3 \pm 0.1$ & $6.3 \pm 0.7$ & $2.5 \pm 0.1$ & $2.7 \pm 0.8$ & $5.4 \pm 0.5$ & $>100$ \\
\hline $3 c$ & $0.05 \pm 0.04$ & $0.24 \pm 0.04$ & $1.1 \pm 0.2$ & $0.23 \pm 0.05$ & $0.21 \pm 0.03$ & $0.54 \pm 0.08$ & $4.6 \pm 0.2$ \\
\hline $4 c$ & $0.02 \pm 0.01$ & $0.44 \pm 0.02$ & $0.3 \pm 0.1$ & $0.21 \pm 0.07$ & $14 \pm 4$ & $>100$ & $>100$ \\
\hline
\end{tabular}

[a] Data after $96 \mathrm{~h}$ of incubation. Stock solutions in DMSO for all complexes; stock solutions in $\mathrm{H}_{2} \mathrm{O}$ for cisplatin. A2780 and OVCAR5 (cisplatin-sensitive ovarian cancer cell lines), A2780cis (cisplatin-resistance ovarian cancer cell line), A549 (lung cancer cell line), A375 (malignant melanoma cell line), DLD1 (colon cancer cell line), MRC-5 (normal lung fibroblasts).

\section{Antiproliferative activity on mouse liver organoids and human ovarian cancer tumoroids}

Complex 4c was chosen for further studies because of its low cytotoxicity on human lung fibroblasts and the very high anticancer activity toward ovarian cancer cells.

It is important to underline that the research on new chemotherapeutic agents for the treatment of ovarian cancer is still of fundamental importance, being one of the most lethal tumors for women worldwide. As a matter of fact, the platinumbased therapy is currently the main first line treatment, but unfortunately almost all patients relapse with a 5-year survival rate of less than 40 percent.

\section{Liver organoid Toxicity}

The correlation between hepatotoxicity and chemotherapy is well documented although the etiology of various agents remains mostly unexplained. ${ }^{[26]}$ Here we utilized normal liver organoids to assess their viability at different concentrations of compound $\mathbf{4 c}$. Organoids are reported in literature as a reliable model to determine the $\mathrm{IC}_{50}$ of chemical compounds in different cancer types ${ }^{[27]}$ and to assess liver toxicity. ${ }^{[28-29]}$

Organoids were characterized by immunohistochemistry for premature (SOX9 and cytokeratin 19) and mature (HNF4a, albumin and E-cadherin) hepatocyte markers as previously published. ${ }^{[29]}$ Cisplatin showed a strong cytotoxicity on organoids with an $\mathrm{IC}_{50}$ value of $0.03 \pm 0.01 \mu \mathrm{M}$. Compound $4 \mathrm{c}$ had about 100 fold less toxicity $\left(\mathrm{IC}_{50}=3 \pm 2 \mu \mathrm{M}\right)$. The values confirmed the data obtained on cell lines and strongly support the use of compound $\mathbf{4 c}$ for future clinical applications.

\section{Anticancer activity on human ovarian cancer tumoroids}

Among ovarian cancers, the high-grade serous subtype (HGSOC) is the most common with the worst 5-year survival rate. ${ }^{[21]}$ Current lines of therapies are not effective, demanding for novel drugs to overcome innate or acquired resistance that limit treatment efficacy and in turn, increasing toxicity.

Taking advantages from organoid technology, three HGSOC patients were selected to test the efficacy of compound $\mathbf{4 c}$.

The tumoroids were derived primarily from solid tumors extracted from primary (OV-A and OV-C) and metastatic (OV-B) sites. Hematoxylin and eosin (H\&E) staining confirm a similarity between tumoroids and parental tumors at morphologic and cytologic levels. Typical markers of HGSOC are evident such as nuclear pleomorphism, prominent nucleoli, and dense chromatin. IHC analysis confirmed the expression of the Müllerian marker PAX8 typical of this type of tumor (Figure 4). ${ }^{[23]}$

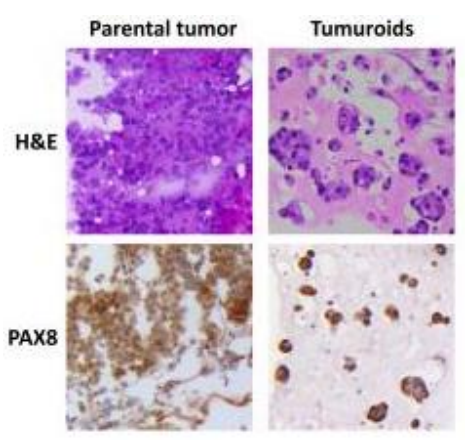

Figure 4. Example of characterization by H\&E staining and PAX8 marker of parental tumor and tumoroids (OV-A patient).

Furthermore, the $\mathrm{IC}_{50}$ of carboplatin was evaluated, as in clinical standard therapy (Table 2). 
Table 2. $\mathrm{IC}_{50}(\mu \mathrm{M})$ of $\mathbf{4 c}$ and carboplatin on ovarian cancer tumoroids after 96 $\mathrm{h}$ of incubation.

\begin{tabular}{|c|c|c|c|}
\hline \multirow{2}{*}{ Compound } & \multicolumn{3}{|c|}{ Patients } \\
\cline { 2 - 4 } & OV-A & OV-B & OV-C \\
\hline Carboplatin & $>100$ & $>100$ & $30 \pm 8$ \\
\hline 4c & $3 \pm 2$ & $3 \pm 2$ & $2 \pm 1$ \\
\hline
\end{tabular}

Contrary to carboplatin, compound $\mathbf{4 c}$ was very active on tumoroids with all values below $4 \mu \mathrm{M}$. Considering that almost all patients during the clinical course will not respond to carboplatin, compound $\mathbf{4 c}$ could be considering more than an opportunity for patients. In addition, the low activity on normal liver organoids suggest an excellent profile for long term therapy.

\section{Mechanism of cell death}

The mixed NHC/PTA complex $4 \mathrm{c}$ was also chosen as model compound for further mechanism studies based on immunofluorescence techniques.

In particular, DNA damage, cytochrome $\mathrm{C}$ release and mitochondrial membrane depolarization were analyzed to clarify the biological target of the palladium allyl complexes reported in this work. To strengthen the data, the biological experiments were carried out by a kinetic analysis at different timepoints. With this approach, it is possible to determine the primary biological effects generated directly by the compounds.

\section{DNA damage}

To evaluate the DNA damage, a well-established approach is represented by the analysis of the phosphorylation of histone $\mathrm{H} 2 \mathrm{AX}(\mathrm{yH} 2 \mathrm{AX}) .{ }^{[30]}$

Phosphorylation of $\mathrm{H} 2 \mathrm{AX}$ occurs immediately after the presence of a DNA break and involves the formation of clusters of proteins at the site of damage, called DNA damage response foci.

In this respect, A2780 cells were treated with 4c (10, 20 and 80 $\mathrm{nM})$ and cisplatin ( $10 \mu \mathrm{M}$ as positive control) for 3,6 and 12 hours. As shown in Figure 5, the cells treated with compound $\mathbf{4 c}$ do not show phosphorylation of Ser139 of histone H2AX after 12 hours. On the contrary, DNA damage in cells treated with cisplatin is already evident after 3 hours (green foci in the nucleus).

These results suggest that DNA is unlikely to be a major molecular target of $\mathbf{4 c}$.

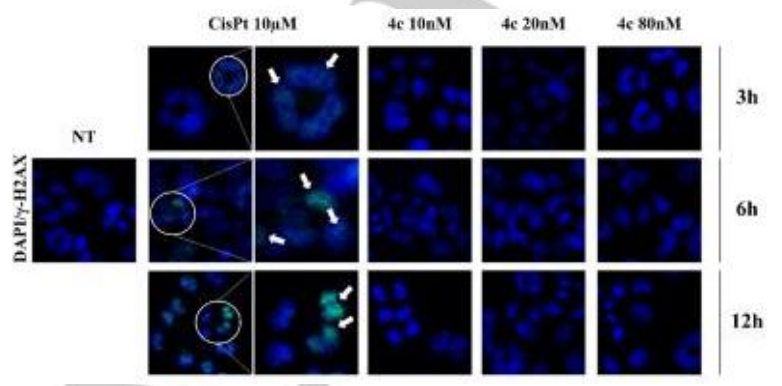

Figure 5. Assay on DNA damage after incubation of A2780 cell line with $4 \mathbf{c}$ (10, 20 and $80 \mathrm{nM})$ and $\mathrm{CisPt}(10 \mu \mathrm{M})$. Arrows indicate nuclear foci of Ser139Histone H2AX.

\section{Cytochrome $\mathrm{C}$ release}

Mitochondria play a fundamental role in the initiation of apoptosis and the release of different proteins that are usually present in their intermembrane space (i.e. cytochrome $\mathrm{C}$ and adenylate kinase-2) has been observed during the early stages of apoptotic cell death. ${ }^{[31]}$

For this reason, the release of cytochrome $C$ is one of the most widely used assays for assessing damage to mitochondria.

This early event was studied by immunofluorescence and the results are summarized in Figure 6.

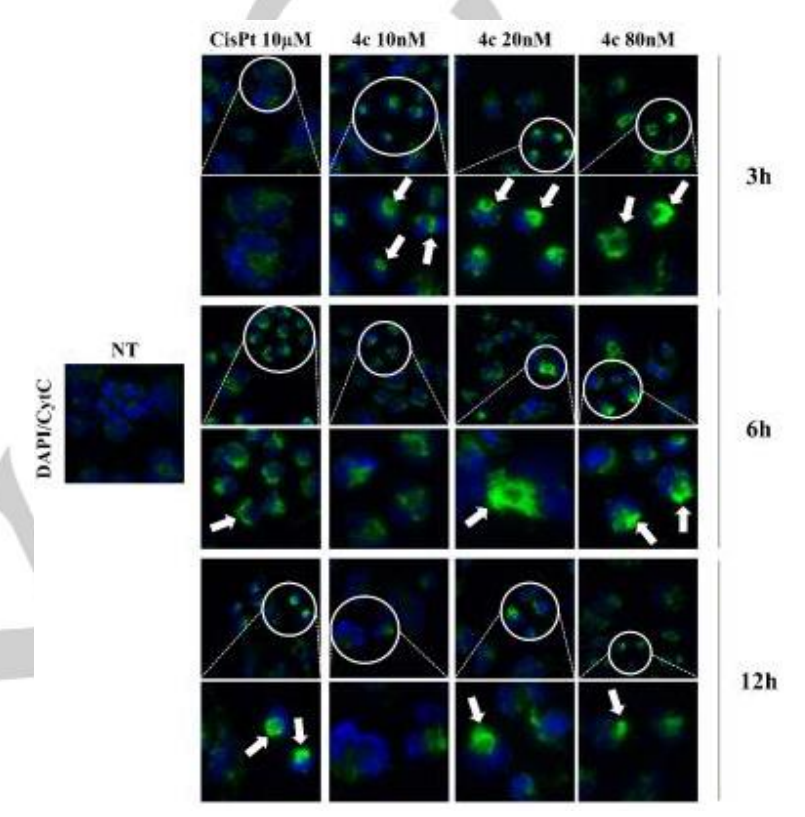

Figure 6. Immunofluorescence analysis of cytochrome $C$ release after incubation of $A 2780$ cells with $4 \mathrm{c}(10,20$ and $80 \mathrm{nM})$ and CisPt $(10 \mu \mathrm{M})$. Arrows indicate cytochrome $\mathrm{C}$ release.

The collected images have shown the release of cytochrome $\mathrm{C}$ already after 3 hours in the case of A2780 cell line treated with compound 4c. Moreover, this result is clearly evident even at the lowest concentration used (10 $\mathrm{nM})$ and decreases starting from 12 hours after treatment.

For cisplatin $(10 \mu \mathrm{M})$, a slight release of the aforementioned protein occurs after 3 hours but is clearly evident only after 6 hours from the treatment of the cells.

\section{Mitochondrial membrane depolarization}

Loss of mitochondrial membrane potential is another indication of apoptosis proceeding through events involving mitochondria. In this context, JC- 1 dye is widely used to monitor the integrity of the mitochondrial membrane as it exhibits a potential-dependent accumulation. ${ }^{[32]}$

This molecule is characterized by a red emission when it forms the aggregates with the mitochondrial membrane and a green emission when the membrane is depolarized.

Consequently, the mitochondrial depolarization is indicated by a decrease in the red/green fluorescence intensity ratio.

Based on the timing observed in the cytochrome $C$ release assay, A2780 cells were treated for 1 and 2 hours with the compound $\mathbf{4 c}$ 
$(10,20$ and $80 \mathrm{nM})$, cisplatin $(10 \mu \mathrm{M})$ and hydrogen peroxide $(1 \mathrm{mM})$. The latter is known to strongly alter the membrane potential and is therefore used as a positive control. ${ }^{[33]}$

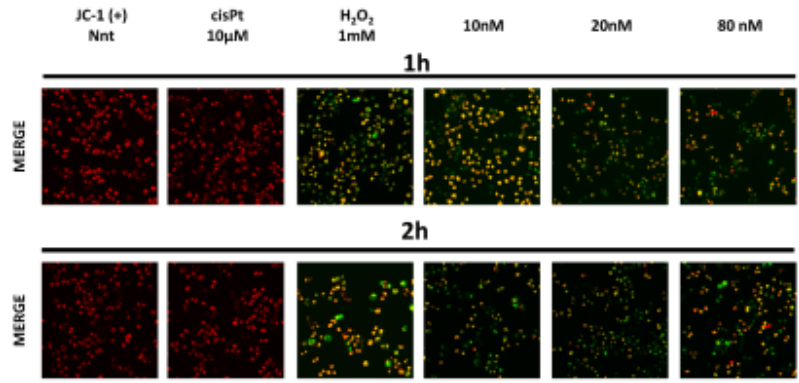

Figure 7. Effect of $4 \mathrm{c}(10,20$ and $80 \mathrm{nM})$, Cisplatin $(10 \mu \mathrm{M})$ and $\mathrm{H}_{2} \mathrm{O}_{2}(1 \mathrm{mM})$ on mitochondrial potential of A2780 cell line after incubation for 1 and 2 hours with JC-1 dye.

The results summarized in Figure 7 show the ability of hydrogen peroxide and compound $\mathbf{4 c}$, even at very low concentrations, to cause the depolarization of the mitochondrial membrane already after 1-2 hours. On the other hand, cisplatin shows no appreciable alteration at a mitochondrial level.

The immunofluorescence experiments reported above prove that, in a time sequence, mitochondria are damaged before DNA by our palladium allyl compounds as opposed to what happens for cisplatin.

This behavior is not general for palladium complexes and in a previous paper we have shown that in the case of palladacyclopentadienyl derivatives this progression of events is inverted. ${ }^{[18 \mathrm{~b}]}$

This suggests that the nature of organic fragment bonded to the metal centre plays a crucial role in the biological activity of the complex.

\section{Conclusion}

In this paper we have synthesized a new class of palladium complexes assembling three different components: a $\mathrm{N}$ trifluoromethyl $\mathrm{N}$-heterocyclic carbene, a water-soluble phosphine (PTA) and an organometallic fragment $\mathrm{Pd}\left(\eta^{3}\right.$-allyl). Each component has been introduced with the aim to improve the biocompatibility and the selective anticancer activity of these compounds. The results obtained are particularly encouraging and the cytotoxicity of our complexes toward six different tumor cell lines is in many cases significantly higher than cisplatin. Moreover, this efficiency is favorably combined with a poor effect on normal cells (MRC-5 fibroblasts). It is worthwhile to point out that the substitution of PTA with $\mathrm{PPh}_{3}$ induce a general increase of cytotoxicity but implicate also a drastic reduction of selectivity toward cancer cells. Such an effect could derive from the minor stability of the complexes coordinating the aromatic phosphine with a decomposition pathway that produce triphenylphosphinoxide. This oxide has an intrinsic toxicity that can damage indiscriminately cancer and healthy cells. Furthermore, we have observed that the introduction of a methyl substituent on 2-position of allyl fragment has a detrimental effect on the antiproliferative activity of the corresponding compounds. All these facts make us think that the key of the bio-activity of our complexes could be the attack to allyl fragment carried out by a nucleophile present in the bio-target, which is favored by the presence of electron-withdrawing substituents $\left(\mathrm{CF}_{3}\right)$ on the $\mathrm{NHC}$ ligands and penalized (electronically and sterically) by that one of methyl substituent on allyl group. Therefore "allylation" of a strategic biomolecule could be one of the most important reasons of the cytotoxicity of these palladium complexes.

One of the most efficient compounds (4c) has been also assessed in a series of biological experiments to determine its cellular targets.

This data, in some way, agrees with the results of biological tests carried out to determine the primary cellular target of our compounds. A kinetics analysis at different time point have proved that the first cellular damage is not on DNA ( $\mathrm{YH} 2 \mathrm{AX}$ test) but on mitochondria (JC-1 and cytochrome $\mathrm{C}$ tests). This different mechanism of action in comparison with cisplatin and derivatives could make these novel compounds suitable to treat those types of tumors with spontaneous or induced resistance to classical platinum drugs.

Finally, the effectiveness of the new allyl-palladium compounds has been verified also on more complex structures as ovarian cancer tumoroids, obtained by cancer tissues of three HGSOC patients. The results are promising and in all three cases complex 4c is resulted definitely more active than carboplatin. Moreover, the low activity on normal liver organoids is a good premise in view of a therapeutic application.

\section{Acknowledgements}

FR was financially supported by Fondazione AIRC per la Ricerca sul Cancro (Grant AIRC IG23566) and VC from Ministero della Salute - Ricerca Corrente.

Keywords: N-trifluoromethyl carbenes • Ovarian cancer • Organoids • Palladium allyl complexes • Allylation

[1] World Health Organization, Latest global cancer data, Geneva, 2018.

[2] F.G. Herrera, J. Bourhis, G. Coukos, CA: Cancer J. Clin. 2017, 2 (67), 65.

[3] M. Galanski, M. A. Jakupec, B. K. Keppler, Curr. Med. Chem. 2005, 12, 2075.

[4] B. Rosenberg, L. Vancamp, J. E. Trosko, V. H. Mansour, Nature 1969 222, 385.

[5] a) S. E. Sherman, S. J. Lippard, Chem. Rev. 1987, 87, 1153; b) M. A. Fuertes, C. Alonso, J. M. Pérez, Chem. Rev. 2003, 103, 645; c) J. Reedijk, Proc. Natl. Acad. Sci. 2003, 100, 3611; d) D. Wang, S. J. Lippard, Nat. Rev. Drug Discov. 2005, 4, 307.

[6] Y. Jung, S. J. Lippard, Chem. Rev. 2007, 107 (5), 1387

[7] a) A. R. Kapdi, I. J. Fairlamb, Chem. Soc. Rev. 2014, 43, 4751; b) F. Huq, H. Tayyem, P. Beale, J. Q. Yu, J. Inorg. Biochem. 2007, 101, 30; c) J. Spencer, A. Casini, O. Zava, R. P. Rathnam, S. K. Velhanda, M. Pfeffer S. K. Callear, M. B. Hursthouse, P. J. Dyson, Dalton Trans. 2009, 10731; d) S. Ray, R. Mohan, J. K. Singh, M. K. Samantaray, M. M. Shaikh, D. Panda, P. Ghosh, J. Am. Chem. Soc. 2007, 129, 15042; e) T.-H. Fong, C.-N. Lok, C. Y.-S. Chung, Y.-M. E. Fong, P.-K. Chow, P.-K. Wan, C.-M Che, Angew. Chem. Int. Ed. 2016, 55, 11935.

[8] S. D. Gonzàlez, N. Marion, S. P. Nolan, Chem. Rev. 2009, 109, 3612.

[9] L. Oehninger, R. Rubbiani, I. Ott, Dalton Trans. 2013, 42(10), 3269. 
[10] a) D. Marchione, L. Belpassi, G. Bistoni, A. Macchioni, F. Tarantelli, D. Zuccaccia, Organometallics 2014, 33, 4200; b) D. J. Nelson, S. P. Nolan, Chem. Soc. Rev. 2013, 42, 6723.

[11] a) A. Liske, K. Verlinden, H. Buhl, K. Schaper, C. Ganter, Organometallics 2013, 32, 5269; b) P. S. Engl, R. Senn, E. Otth, A. Togni, Organometallics 2015, 34, 1384; c) P. S. Engl, C. B. Santiago, C. P. Gordon, W. Liao, A Fedorov, C. Copéret, M. S. Sigman, A. Togni, J. Am. Chem. Soc. 2017 139, 13117

[12] D. O'Hagan, Chem. Soc. Rev. 2008, 37, 308.

[13] a) N. A. Meanwell, J. Med. Chem. 2010, 54(8), 2529; b) J. Wang, M. Sánchez-Roselló, J. L. Aceña, E. Al, Chem. Rev. 2014, 114(4), 2432; c) S. Purser, P. R. Moore, S. Swallow, V. Gouverneur, Chem. Soc. Rev. 2008, 37, 320.

[14] a) D. A. Krogstad, J. Cho, A. J. DeBoer, J. A. Klitzke, W. R. Sanow, H. A. Williams, J. A. Halfen, Inorg. Chim. Acta 2006, 359, 136; b) E. Vergara, S. Miranda, F. Mohr, E. Cerrada, R. T. Tiekink, P. Romero, A. Mendía, M. Laguna, Eur. J. Inorg. Chem. 2007, 2926; c) J. Lasri, M. J. Fernández Rodríguez, M. F. C. Guedes da Silva, P. Smolenski, M. N. Kopylovich, J. J. R. Fraústo da Silva, A. J. L. Pombeiro, J. Organomet. Chem. 2011, 696 3513; d) M. Carreira, R. Calvo-Sanjuan, M. Sanauí, I. Marzo, M. Contel, Organometallics 2012, 31, 5772; e) E. Guerrero, S. Miranda, S. Luüttenberg, N. Froöhlich, J. Koenen, F. Mohr, E. Cerrada, M. Laguna, A. Mendía, Inorg. Chem. 2013, 52, 6635; f) J. Braddock-Wilking, S. Acharya, N. P. Rath, Polyhedron 2014, 79, 16; g) V. Ferretti, M. Fogagnolo, A. Marchi, L. Marvelli, F. Sforza, P. Bergamini, Inorg. Chem. 2014, 53 (10), 4881.

[15] a) B. Crociani, S. Antonaroli, F. Di Bianca, L. Canovese, F. Visentin, P. Uguagliati, J. Chem. Soc. Dalton Trans. 1994, 1145; b) L. Canovese, F. Visentin, P. Uguagliati, G. Chessa, A. Pesce, J. Organomet. Chem. 1998, 566, 61; c) L. Canovese, G. Chessa, C. Santo, F. Visentin, P. Uguagliati, Organometallics 2002, 21, 4342; d) F. Visentin, A. Togni, Organometallics 2007, 26, 3746; e) L. Canovese, F. Visentin, C. Santo, G. Chessa, V. Bertolasi, Organometallic 2010, 29, 3027; f) L. Canovese, F. Visentin, C. Levi, A. Dolmella, Dalton Trans. 2011, 40, 966; g) L. Canovese, F. Visentin, C. Levi, C. Santo, V. Bertolasi. J. Organomet. Chem. 2013, 732, 27; h) L. Canovese, F. Visentin, C. Santo, V. Bertolasi, Organometallics 2014, 33, 1700; i) L. Canovese, F. Visentin, T. Scattolin, C. Santo, V. Bertolasi, Polyhedron 2016, 119, 377.

[16] a) E. Negishi, Handbook of Organopalladium Chemistry for Organic Synthesis, John Wiley \& Sons, Inc., New York, 2002; b) C. M. Zinser, F. Nahra, M. Brill, R. E. Meadows, D. B. Cordes, A. M. Z. Slawin, S. P. Nolan, C. S. J. Cazin, Chem. Commun. 2017, 53, 7990; c) F. Izquierdo, A. Chartoire, S. P. Nolan, ACS Catal. 2013, 3, 2190.

[17] a) T. Scattolin, I. Caligiuri, L. Canovese, N. Demitri, R. Gambari, I. Lampronti, F. Rizzolio, C. Santo, F. Visentin, Dalton Trans. 2018, 47, 13616; b) T. Scattolin, L. Canovese, F. Visentin, S. Paganelli, P. Canton, N. Demitri, Appl. Organomet. Chem. 2018, 32, e4034.

[18] a) T. Scattolin, S. Giust, P. Bergamini, I. Caligiuri, L. Canovese, N. Demitri, R. Gambari, I. Lampronti, F. Rizzolio, F. Visentin, Appl. Organomet. Chem. 2019, 33, e4902; b) T. Scattolin, I. Caligiuri, N. Mouawad, M. EI Boustani, N. Demitri, F. Rizzolio, F. Visentin, Eur. J. Med. Chem. 2019, 179, 325; c) T. Scattolin, N. Pangerc, I. Lampronti, C. Tupini, R. Gambari, L. Marvelli, F. Rizzolio, N. Demitri, L. Canovese, F. Visentin, J. Organomet. Chem. 2019, 899, 120857; d) T. Scattolin, G. Moro, F. Rizzolio, C. Santo, L. M. Moretto, F. Visentin, ChemistrySelect 2019, 4, 10911.
[19] M. Matano, S. Date, M. Shimokawa, A. Takano, M. Fujii, Y. Ohta, T. Watanabe, T. Kanai, T. Sato, Nat. Med. 2015, 21(3), 256.

[20] M. van de Wetering, H. E. Francies, J. M. Francis, G. Bounova, F. lorio A. Pronk, W. van Houdt, J. van Gorp, A. Taylor-Weiner, L. Kester, A. McLaren-Douglas, J. Blokker, S. Jaksani, S. Bartfeld, R. Volckman, P. van Sluis, V. S. Li, S. Seepo, C. Sekhar Pedamallu, K. Cibulskis, S. L. Carter, A. McKenna, M. S. Lawrence, L. Lichtenstein, C. Stewart, J. Koster, R. Versteeg, A. van Oudenaarden, J. Saez-Rodriguez, R. G. Vries, G. Getz, L. Wessels, M. R. Stratton, U. McDermott, M. Meyerson, M. J. Garnett, H. Clevers, Cell. 2015, 161(4), 933

[21] D. D. Bowtell, S. Böhm, A. A. Ahmed, P. J. Aspuria, R. C. Bast, V. Beral, J. S. Berek, M. J. Birrer, S. Blagden, M. A. Bookman, J. D. Brenton, K. B. Chiappinelli, F. C. Martins, G. Coukos, R. Drapkin, R. Edmondson, C. Fotopoulou, H. Gabra, J. Galon, C. Gourley, V. Heong, D. G. Huntsman, M. Iwanicki, B. Y. Karlan, A. Kaye, E. Lengyel, D. A. Levine, K. H. Lu, I. A. McNeish, U. Menon, S. A. Narod, B. H. Nelson, K. P. Nephew, P. Pharoah, D. J. Powell, P. Ramos, I. L. Romero, C. L. Scott, A. K. Sood, E. A. Stronach, F. R. Balkwill, Nat. Rev. Cancer. 2015, 15(11), 668.

[22] R. Perets, G. A. Wyant, K. W. Muto, J. G. Bijron, B. B. Poole, K. T. Chin, J. Y. Chen, A. W. Ohman, C. D. Stepule, S. Kwak, A. M. Karst, M. S. Hirsch, S. R. Setlur, C. P. Crum, D. M. Dinulescu, R. Drapkin, Cancer Cell. 2013, 24(6), 751.

[23] S. J. Hill, B. Decker, E. A. Roberts, N. S. Horowitz, M. G. Muto, M. J. Worley, C. M. Feltmate, M. R. Nucci, E. M. Swisher, H. Nguyen, C. Yang, R. Morizane, B. S. Kochupurakkal, K. T. Do, P. A. Konstantinopoulos, J. F. Liu, J. V. Bonventre, U. A. Matulonis, G. I. Shapiro, R. S. Berkowitz, C. P. Crum, A. D. D'Andrea, Cancer Discov. 2018, 8(11), 1404

[24] O. Kopper, C. J. de Witte, K. Lõhmussaar, J. E. Valle-Inclan, N. Hami, L. Kester, A. V. Balgobind, J. Korving, N. Proost, H. Begthel, L. M. van Wijk, S. A. Revilla, R. Theeuwsen, M. van de Ven, M. J. van Roosmalen, B. Ponsioen, V. W. H. Ho, B. G. Neel, T. Bosse, K. N. Gaarenstroom, H. Vrieling, M. P. G. Vreeswijk, P. J. van Diest, P. O. Witteveen, T. Jonges, J. L. Bos, A. van Oudenaarden, R. P. Zweemer, H. J. G. Snippert, W. P. Kloosterman, H. Clevers, Nat. Med. 2019, 25(5), 838.

[25] Atochem. Letter from Atochem North America Inc. to U.S. EPA regarding toxicity studies of triphenylphosphine and triphenylphosphine oxide w/attachments \& cover letter dated 102292 Bio/Dynamics Inc NTIS/OTS0571918, 1992

[26] J. Floyd, I. Mirza, B. Sachs, M. C. Perry, Semin. Oncol. 2006, 33(1), 50.

[27] E. Driehuis, S. Kolders, S. Spelier, K. Lõhmussaar, S. M. Willems, L. A. Devriese, R. de Bree, E. J. de Ruiter, J. Korving, H. Begthel, J. H. van Es, V. Geurts, G. W. He, R. H. van Jaarsveld, R. Oka, M. J. Muraro, J. Vivié, M. M. J. M. Zandvliet, A. P. A. Hendrickx, N. lakobachvili, P. Sridevi, O. Kranenburg, R. van Boxtel, G. J. P. L. Kops, D. A. Tuveson, P. J. Peters, A. van Oudenaarden, H. Clevers, Cancer Discov. 2019, 9(7) 852.

[28] N. Prior, P. Inacio, M. Huch, Gut. 2019, 68(12), 2228.

[29] S. Palazzolo, M. Hadla, C. Russo Spena, I. Caligiuri, R. Rotondo, M. Adeel, V. Kumar, G. Corona, V. Canzonieri, G. Toffoli, F. Rizzolio, Cancers 2019, 11, 1997.

[30] M. Fragkos, J. Jurvansuu, P. Beard, Mol. Cell. Biol. 2009, 29, 2828.

[31] M. Ott, J. D. Robertson, V. Gogvadze, B. Zhivotovsky, S. Orrenius, Proc. Natl. Acad. Sci. U.S.A. 2002, 99(3), 1259.

[32] F. Sivandzade, A. Bhalerao, L. Cucullo, Bio Protoc. 2019, 9(1), e3128.

[33] W. H. Park, Oncology Reports 2014, 31, 2413. 


\section{Entry for the Table of Contents}

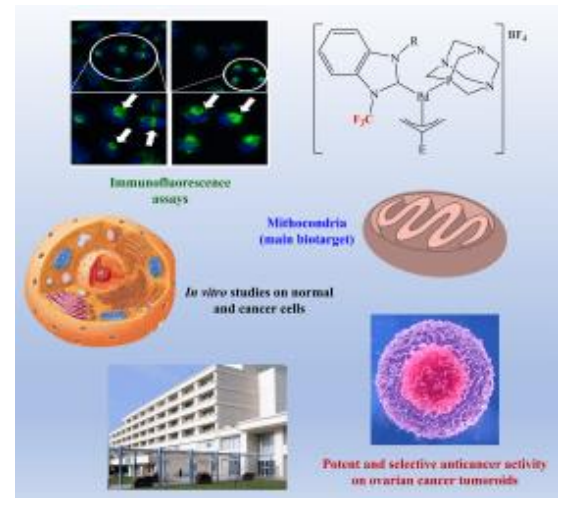

The first palladium organometallic compounds bearing $N$-trifluoromethyl $N$-heterocyclic carbenes have been synthesized. These $\eta^{3}$ allyl complexes are potent antiproliferative agents toward different cancer lines (the most part of $\mathrm{IC}_{50}$ falls in the range of $0.02-0.5 \mu \mathrm{M}$ ) and their primary cellular target is not DNA but mitochondria.

Their effectiveness has been even verified on ovarian cancer tumoroids derived from patients. 